\title{
Géneros de texto e as dimensões do suporte
}

\author{
Rute Rosa \& Matilde Gonçalves ${ }^{1}$ \\ CLUNL e NOVA FCSH
}

\begin{abstract}
:
Situated within text and discourse linguistics, this paper focuses on presentation and discussion of the relations between medium and text genres. Firstly, a categorization of the dimensions of the medium is presented. Finally, based on a qualitative analysis, this article discusses the role of medium in different textual genres - scientific article, medication package insert, interview, and graffiti.
\end{abstract}

Keywords: text genres, medium, sociodiscursive interactionism, text and discourse linguistics

Palavras-chave: géneros de texto, suporte, interacionismo sociodiscursivo, linguística do texto e do discurso

\section{Introdução}

Neste artigo, aborda-se uma questão ainda pouco trabalhada nos atuais campos de estudo dos géneros: as relações entre géneros e suporte. Atualmente, é consensual que o suporte é essencial para a circulação dos textos na sociedade, constituindo uma das propriedades dos géneros e um dos marcadores materiais que maior influência tem nos textos (Marcuschi, 2003; Miranda, 2010).

Segundo Maingueneau (2002a: 70), a tradicional oposição oral/escrita é uma distinção simplificadora e sumária, não contemplando, por exemplo, as diferenças entre os textos impressos e manuscritos, sendo também, assim, insuficiente para dar conta das relações entre géneros e suporte. $\mathrm{Na}$ nossa perspetiva, para tal, é necessário distinguir as dimensões inerentes a esta propriedade genológica. Neste sentido, a partir de trabalhos desenvolvidos no âmbito de uma tese de doutoramento (Rosa, 2020), de um pós-doutoramento (Gonçalves, 2010-2018) e de um projeto de investigação financiado sobre divulgação de ciência (Promoção da Literacia Científicia, 2016-2017), o objetivo deste artigo é apresentar uma proposta de classificação das dimensões do suporte, refletindo-se sobre o modo como estas se relacionam com diferentes géneros de texto.

Para cumprir este objetivo, por um lado, de entre as perspetivas teóricas que acolhem a noção de género, privilegiamos a que é apresentada e defendida no quadro do Interacionismo Sociodiscursivo (ISD) (Bronckart, [1997]1999; Coutinho, 2005; 2006) e, por outro, consideramos trabalhos desenvolvidos a partir de diferentes quadros e perspetivas teóricas que têm abordado a questão do suporte (Marcuschi, 2003; Maingueneau, 2002a; Miranda, 2010; Gonçalves \& Rosa, 2019; Rosa, 2018; 2020).

Em termos metodológicos, adotando uma abordagem de cunho qualitativo e interpretativo (Rastier, 2001), num primeiro momento, apresenta-se uma proposta de classificação das dimensões do suporte, seguindo-se a discussão sobre o modo como as dimensões consideradas se relacionam com os géneros artigo científico, bula de medicamento, entrevista e graffiti. O artigo está, desta forma, organizado em cinco secções: a presente secção corresponde à introdução; a segunda, dedicada à noção de géneros de texto, diz respeito ao segundo ponto; a terceira secção foca a questão do suporte, no ponto 3.; na quarta secção apresentamos a nossa proposta de classificação das dimensões do suporte, no ponto 4; seguindo-se o subponto 4.1., no qual abordamos as relações

\footnotetext{
${ }^{1} \mathrm{O}$ presente trabalho é financiado por fundos nacionais portugueses, através da FCT - Fundação para a Ciência e Tecnologia, como parte do projeto do Centro de Linguística da Universidade NOVA de Lisboa - UID/LIN/03213/2020 e da bolsa de investigação de Rute Rosa, PD/BD/113974/2015, ao abrigo do Programa de Doutoramento FCT “KRUse - Knowledge, Representation \& Use”.
} 
das dimensões do suporte em diferentes géneros; na quinta secção, fazemos algumas considerações finais em relação ao trabalho apresentado.

\section{Géneros de texto}

No âmbito do quadro teórico do ISD, os géneros de texto são entendidos "como instrumentos ou modelos que [...] se apresentam aos utentes da língua sob a forma de nebulosa (onde coexistem géneros estabilizados e conjuntos de textos sem fronteiras fixas ou nítidas)." (Coutinho, 2006: 4). Esta nebulosa é mutável, tendo em conta que os géneros estão apenas momentaneamente "estabilizados pelo uso", podendo desvincular-se das "motivações que lhes deram origem, para ficarem autónomos e, assim, ficarem disponíveis para a expressão de outras finalidades" (Bronckart, 2005: 62). Conforme Gonçalves (2011: 5), as fases de estabilização e de estabilidade do género são relativas, dado que os géneros estão em contínua evolução, podendo sofrer mudanças em menor ou maior grau. No seguimento do exposto, os géneros surgem a partir de necessidades sociais, cumprindo, desta forma, diferentes finalidades comunicativas, consoante as mudanças que ocorrem no seio das sociedades (Rosa, 2020: 44).

Segundo Miranda (2017: 815-817), os géneros de texto são instrumentos necessários para a “organização do uso da linguagem em unidades de comunicação, ou seja, em textos" (Miranda, 2017: 815). No quadro do ISD, assume-se, desta forma, o pressuposto de que qualquer texto constitui uma ação de linguagem que se concretiza através da interação com um dos modelos de géneros sincronicamente e arquitextualmente disponíveis. Neste sentido, as ações de linguagem de que resultam os textos empíricos constituem "unidades psicológicas sincrónicas que reúnem as representações de um agente sobre contextos de ação, em seus aspetos físicos, sociais e subjetivos" (Bronckart, [1997]1999: 107). Conforme sublinha Bronckart (2005: 64-65), na realização de uma ação de linguagem, o agente da ação seleciona o modelo de género que lhe parece mais adequado à situação comunicativa, mediante as representações que tem da mesma, adaptando esse modelo às propriedades específicas da situação. O texto empírico é, desta forma, resultado deste duplo processo de adoção e adaptação, apresentando, por isso, propriedades do género selecionado e características que decorrem das particularidades da situação da ação. As representações que o agente dispõe inscrevem-se em três conjuntos: o dos parâmetros contextuais de ordem física, o dos parâmetros de ordem social e subjetiva, bem como o conjunto de outras representações e conhecimentos. Nesta perspetiva, para o ISD, o contexto diz respeito aos parâmetros físicos e sociossubjetivos que influenciam a construção textual. Quanto aos parâmetros contextuais de ordem física, este conjunto integra: o emissor $(\mathrm{a}(\mathrm{s})$ pessoa(s) ou máquina que produz(em) o texto); o recetor $(\mathrm{a}(\mathrm{s})$ pessoa(s) que irá (ão) receber o texto); o momento e o lugar em que o texto é produzido. Relativamente ao contexto sociossubjetivo, neste conjunto, Bronckart inclui quatro parâmetros: o quadro social (instituição ou quadro da interação); o papel social assumido pelo emissor (enunciador) e o que é atribuído ao recetor (destinatário); a finalidade (efeito que o texto deverá produzir no destinatário (Bronckart, [1997]1999: 93)). Já as outras representações e conhecimentos contemplam, entre outros elementos, os conhecimentos que o agente tem relativamente aos temas verbalizados nos textos, sendo que nestes podem ser tematizados referentes do mundo físico, do mundo social, do mundo subjetivo ou podem articular referentes de diferentes mundos (Bronckart, [1997]1999: 97). Embora não seja incluído o suporte neste conjunto de parâmetros contextuais, este, como mencionado inicialmente, constitui uma propriedade dos géneros e um dos marcadores materiais que maior influência tem nos textos (Miranda, 2010), sendo, por isso, necessário aprofundar o conhecimento sobre as relações entre géneros de texto e suporte. 


\section{Suporte}

Ainda que a história dos sistemas orais e escritos da sociedade humana evidencie que o suporte é indissociável dos processos de produção e receção textuais, até há algumas décadas, a questão do suporte estava confinada à dicotomia oral/escrito (Bronckart, [1997]1999: 184-185). Com o exponencial desenvolvimento da informática e dos meios audiovisuais, surgiram novos suportes de produção e receção textuais (De Angelis \& Gonçalves, no prelo; Gonçalves, 2011; Rosa, 2020). A emergência do suporte digital mudou, desta forma, a natureza dos textos, alterando também, significativamente, os nossos hábitos culturais e cognitivos (De Angelis, 2018: 459). Neste sentido, o surgimento do suporte digital trouxe uma outra forma de organização dos diversos recursos semióticos (linguísticos e imagéticos), tendo implicações nos percursos de leitura e de compreensão textual e, consequentemente, na construção do conhecimento (cf. Gonçalves, 2013). Em Gonçalves \& Rosa (2019: 585), a partir de uma análise comparativa de textos produzidos em dois tipos de suporte (impresso e digital), conclui-se que uma mudança de suporte tem implicações no plano de texto, tanto nos conteúdos tematizados como na sua organização, e que estas geram diferentes percursos de leitura e interpretação textual.

Apesar de a dicotomia oral/escrito contemplar diferenças importantes entre estas duas modalidades de produção textual, constitui uma distinção simplificadora e sumária, dado que exclui, por exemplo, os textos escritos para serem lidos posteriormente, ou ainda as diferenças entre os textos impressos e manuscritos, sendo também, assim, insuficiente para dar conta das particularidades das formas de construção textual que surgiram com a emergência do suporte digital (Maingueneau, 2002a: 70).

Para Maingueneau (2002a: 70-71), o suporte não é uma dimensão acessória, não devendo, por isso, ser entendido como mero meio de transmissão do discurso. Trata-se de uma dimensão essencial da comunicação verbal, tendo em conta que influencia os conteúdos e usos que dele fazemos. De acordo com o autor, uma mudança de suporte pode modificar um género.

Uma modificação do suporte material de um texto modifica radicalmente um gênero do discurso: um debate político pela televisão é um gênero de discurso totalmente diferente de um debate em uma sala para um público exclusivamente formado pelos ouvintes presentes. O que chamamos "texto" não é, então, um conteúdo a ser transmitido por este ou aquele veículo, pois o texto é inseparável de seu modo de suporte/transporte e de estocagem, logo, de memorização.

Maingueneau (2002a: 68)

De acordo com Maingueneau, o suporte integra a componente material, uma das cinco componentes em que se inscrevem as regras que definem os géneros (Maingueneau, 2002b). Já Adam (2011) identifica oito componentes de género, integrando o suporte também na componente material. Nesta componente, o autor insere as propriedades relacionadas com o suporte físico e meio de produção e circulação dos textos, assim como os aspetos gráficos (paginação, formatação tipográfica, entre outros) (Adam, 2011: 40-41). Conforme se observa em Silva \& Rosa (2019: 8-10), as componentes dos géneros constituem propriedades de natureza diferenciada que contribuem para a caracterização e delimitação dos géneros textuais. No entanto, "não podemos generalizar a importância e a adequabilidade das componentes a todos os géneros, pois estas manifestam-se de forma muito heterogénea, quer entre géneros, quer num só género, tendo em conta a sua dimensão social e a maleabilidade e a evolução que dela decorrem" (Rosa, 2020: 57). Deste ponto de vista, é importante evidenciar as especificidades do modo como esta propriedade se relaciona com diferentes géneros de texto. 
Menos categórico do que Maingueneau, Marcuschi (2003: 10) refere que, apesar de o suporte poder influenciar a natureza do género, isto não significa que o suporte determine o género, mas sim que o género exige um determinado suporte. Porém, como observa o autor, esta perspetiva é questionável, considerando os casos em que o suporte determina a distinção do género. Para o autor, o suporte implica a existência de lugar físico ou virtual e de um formato cuja função é a de fixar e mostrar o texto (Marcuschi, 2003: 11). Neste sentido, a materialidade (física ou virtual) é inerente ao suporte, ainda que seja mais difícil apreender a materialidade dos textos orais do que dos textos escritos. Além disso, importa sublinhar que à materialidade dos textos é também inerente o espaço que estes ocupam, conforme sublinha De Angelis (2018: 459):

Envisagé en tant qu'écrit, le texte se présente comme un objet linguistique qui occupe un espace. Cet espace n'est pas seulement celui de la ligne d'écriture, mais aussi celui bi- ou tri-dimensionnel de son support.

Assim, o suporte está sempre agregado a um formato específico, como, por exemplo, formato revista, no caso dos suportes impressos, ou, por exemplo, PDF, formato associado a suportes digitais. Essa relação necessária entre formato e suporte deriva do facto de os suportes serem criados para fixar os textos, ou seja, o suporte tem uma função específica (Rosa, 2020: 60). Deste ponto de vista, o suporte como fixador do texto é o que nos permite produzir, divulgar e aceder aos textos, assegurando, assim, a sua existência no espaço e no tempo (Gonçalves \& Rosa, 2019: 573-574). No entanto, em alguns casos, os textos podem ser fixados em suportes ocasionais, isto é, em suportes que não foram criados para fixar os textos, mas que cumprem ocasionalmente essa função, como, por exemplo, as paredes, o pavimento e mobiliário urbanos (Rosa, 2020: 60). Para Marcuschi (2003: 29), estes exemplos constituem casos de suportes incidentais. Embora a possibilidade de a existência de suportes incidentais seja válida, importa ter em conta que nem todos os géneros admitem suportes incidentais, ou seja, as relações entre géneros e suporte não são aleatórias. Aliás, como se frisou, o suporte é um componente genológico determinante para a identidade do género. Consequentemente, o suporte é um traço previsível e característico do género de texto.

A questão que se coloca é saber como dar conta das relações entre géneros e suportes, dado que cada género tem os seus suportes e cada suporte influencia e condiciona os géneros de forma diferenciada. Para tal, é necessário proceder a uma distinção metodológica das dimensões inerentes ao suporte. Conforme se assume em Rosa (2020: 64), o objetivo desta distinção não é apresentar uma categorização estanque, mas evidenciar algumas das possibilidades e impossibilidades das relações entre géneros de texto e suporte. Em conformidade com o objetivo a que nos propomos, no próximo ponto, apresenta-se a proposta de classificação das dimensões do suporte.

\section{As dimensões do suporte}

Nesta proposta, conforme se sistematiza no Quadro 1., consideramos quatro dimensões: contexto, tipo, formato e material ${ }^{2}$, tendo em conta dois contextos em que o género é mobilizado: o da produção e o da circulação. De facto, em alguns casos, observa-se uma coincidência do suporte de produção com o de circulação; todavia, noutros casos, dá-se uma não coincidência entre os dois contextos, como nos textos orais (suporte de produção) e as transcrições desses textos (suporte de circulação), conforme Miranda (2010: 55).

\footnotetext{
${ }^{2}$ Esta proposta foi desenvolvida Rosa (2020: 64), considerando cinco dimensões: contexto, tipo, função, formato e material. Além disso, distinguem-se os suportes convencionais dos suportes ocasionais.
} 


\begin{tabular}{|c|c|c|c|c|}
\cline { 3 - 5 } \multicolumn{1}{|c|}{ Contexto } & Tipo & Formato & Material \\
\hline \multirow{2}{*}{} & \multirow{2}{*}{ Produção } & Impresso & $\begin{array}{c}\text { Livro } \\
\text { Revista } \\
\text { Embalagem... }\end{array}$ & $\begin{array}{c}\text { Papel } \\
\text { Cartão... }\end{array}$ \\
\cline { 3 - 5 } & OU & Digital & $\begin{array}{c}\text { PDF } \\
\text { Word } \\
\text { Hipertextual... }\end{array}$ & Virtual $^{3}$ \\
\cline { 3 - 5 } & \multirow{2}{*}{ Circulação } & Manuscrito & $\begin{array}{c}\text { Livro } \\
\text { Caderno ... }\end{array}$ & $\begin{array}{c}\text { Papel } \\
\text { Cartão } \\
\text { Betão ... }\end{array}$ \\
\cline { 3 - 5 } & & Oral & Ondas sonoras & Ar \\
\cline { 3 - 5 } & & & &
\end{tabular}

Quadro 1. Dimensões do suporte

Na dimensão contexto, como se referiu, distinguimos o contexto de produção do contexto de circulação, pois podem ou não ser coincidentes. Na nossa perspetiva, um suporte, tal como o texto que este veicula, está sempre associado a um contexto, sendo que é o contexto em que é produzido um texto de um determinado género que determina as dimensões seguintes: o tipo, o formato e o material. Neste âmbito, importa sublinhar, como mencionado anteriormente, que os géneros de texto estão associados a determinados contextos de uso, tendo em conta que o duplo processo de adoção e adaptação de um modelo de género depende da forma como o agente da interação perspetiva a situação comunicativa. Essa adaptação implica também, desta forma, a seleção de um suporte, sendo este escolhido, por um lado, de acordo com o género e, por outro, de acordo com a situação de comunicação em que o texto é efetivamente produzido, podendo, por isso, manter ou alterar o suporte convocado pelo género. A segunda dimensão diz respeito ao tipo de suporte e corresponde ao meio de acesso aos textos, ou seja, ao lugar ou modo como o texto é fixado ou mostrado quando acedemos ao mesmo. Neste âmbito, distinguimos quatro tipos: manuscrito, impresso, digital e oral (Rosa, 2020; De Angelis, 2018; Jeanneret \& Souchier, 2005).

O tipo de suporte, por seu lado, é que irá determinar a terceira e quarta dimensões: o formato e material. Enquanto o formato é o objeto concreto ou virtual que cumpre a função de suporte, o material diz respeito à sua constituição. Se, por um lado, o material depende do formato, tendo em conta que cada formato está associado a materiais específicos, por outro, o formato e o material dependem do tipo de suporte, que, por sua vez, como já se referiu, varia consoante o contexto em que é produzido o texto e o género em que o mesmo se inscreve. No Quadro 1., parece existir alguma sobreposição entre os formatos do suporte impresso e os do suporte digital. Todavia, enquanto um livro em suporte impresso tem efetivamente o formato do objeto físico, o formato de um livro em suporte digital é o tipo de ficheiro, como, por exemplo, PDF ou ebook, estando, por isso, associados a materiais distintos.

\footnotetext{
${ }^{3}$ Por virtual entendemos tudo o que é concretizado através de meios eletrónicos. Conforme Levy (1996), a virtualidade gerou novas conceções do espaço, designadamente a desterritorialização, e do tempo, nomeadamente o enfraquecimento do aqui e agora, com a desmaterialização dos objetos.
} 


\subsection{Géneros de texto e as dimensões do suporte}

Neste ponto, procuramos dar conta da relação de diferentes géneros com o suporte, tendo em conta as quatro dimensões descritas. Para tal, consideramos quatro géneros: artigo científico, entrevista, bula de medicamento e graffiti. $\mathrm{O}$ critério de escolha dos géneros é duplo. $\mathrm{O}$ primeiro diz respeito à heterogeneidade dos mesmos, dado que os géneros em causa são mobilizados em contextos sociais distintos, estando também associados a finalidades comunicativas díspares. O segundo é oriundo do estudo destes géneros no âmbito de projetos de investigação referidos, anteriormente, na introdução.

Apresentamos, a seguir, sumariamente, algumas características dos géneros escolhidos para o presente trabalho. Enquanto um texto do género artigo científico tem como finalidade a comunicação e divulgação do trabalho científico, uma bula de medicamento é um texto de caráter instrucional e informativo, destinado a informar os consumidores, de modo a assegurar o uso correto dos medicamentos, ou os profissionais de saúde, para eventuais atualizações que requerem uma prescrição rigorosa. Já a entrevista é um género de cunho jornalístico mobilizado em diferentes meios de comunicação social, caracterizando-se pela organização em sequência dialogal com estruturação pergunta-resposta. Relativamente ao graffiti, este constitui um género com fronteiras bastante fluídas, por um lado, por poder cumprir múltiplos objetivos comunicativos e, por outro, pela heterogeneidade das características dos textos inscritos no género, constituindo o suporte o elemento estabilizador da identidade deste género.

Começando pelas dimensões contexto e tipo de suporte, observa-se que alguns géneros admitem apenas um tipo de suporte na produção, mas diferentes tipos no contexto de circulação. No caso do artigo científico, os textos inscritos no género são produzidos, na maioria dos casos, em suporte digital, mas podem circular em suporte digital ou impresso, como ilustramos no esquema seguinte.

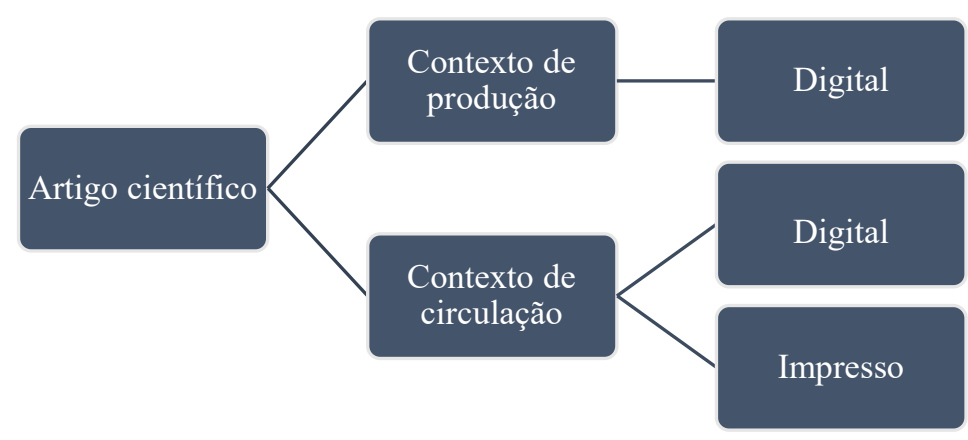

Esquema 1. Género artigo científico e as dimensões contexto e tipo de suporte

Já os exemplares inscritos no género entrevista são habitualmente produzidos em suporte oral, mas podem circular, num segundo momento, em suporte digital e, por fim, em suporte impresso ou oral. No entanto, neste caso, podemos igualmente considerar a possibilidade de a entrevista ser registada em suporte manuscrito ou digital, ainda antes da sua circulação em suporte digital ou impresso. 


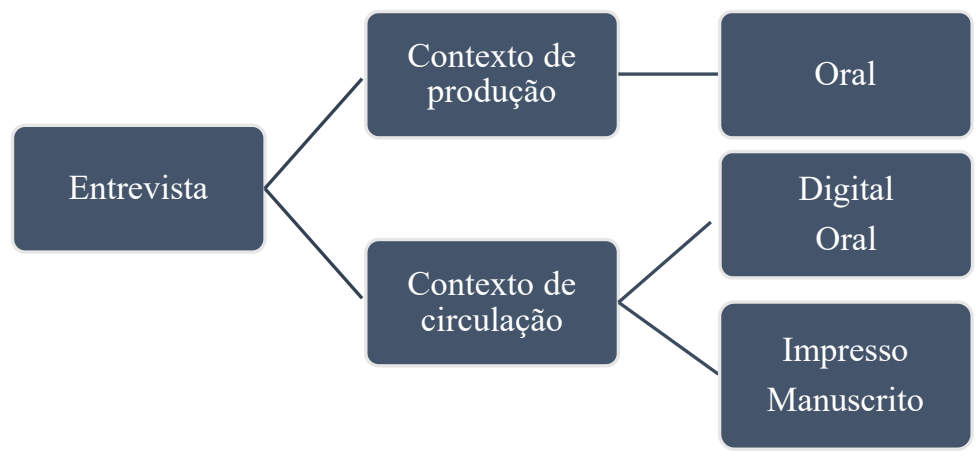

Esquema 2. Género entrevista e as dimensões contexto e tipo de suporte

Neste género, podemos ainda pensar na hipótese de uma sobreposição de diferentes tipos de suporte, como, por exemplo, no caso de uma entrevista televisiva legendada em direto. Embora o suporte primeiro seja o oral, temos também a circulação do texto através de um suporte digital. Neste caso, o contexto de produção e circulação não são apenas coincidentes, mas são também simultâneos, o que se traduz, na nossa perspetiva, numa sobreposição de tipos de suporte. No entanto, se a entrevista, em vez de legendas, for acompanhada por um intérprete de língua gestual, surgem outras questões, tendo em conta a reprodução do texto através de gestos que devem ser visualmente percecionados pelas pessoas com surdez ou deficiência auditiva.

Relativamente ao género bula de medicamento, os exemplares são produzidos em suporte digital, mas podem circular em suporte impresso, sendo indissociável da comercialização de medicamentos, dado que em Portugal é proibida a venda de medicamentos em embalagens que não contenham folhetos informativos ${ }^{4}$. Porém, em alguns países, como, por exemplo, em Portugal e no Brasil, as bulas de medicamento destinadas à informação dos consumidores são também disponibilizadas na internet ${ }^{5}$. Neste caso, os exemplares do género podem também circular em suporte digital. Deste ponto de vista, o tipo de suporte admitido pelo género também depende do contexto socio-histórico em que o mesmo é mobilizado.

\footnotetext{
${ }^{4}$ Em Portugal, o organismo que assegura a regulação neste âmbito é o INFARMED - Autoridade Nacional do Medicamento e Produtos de Saúde, I.P., estando em conformidade com as diretrizes do Parlamento Europeu e do Conselho. Informação disponível em: http://www.infarmed.pt/documents/15786/1068535/035E_DL 176_2006_10ALT.pdf/d2ae048e-547e-4c5c-873e-b41004b9027f

${ }^{5}$ Como, por exemplo, o portal da Anvisa, no Brasil. Sítio web disponível em: http://portal.anvisa.gov.br
} 


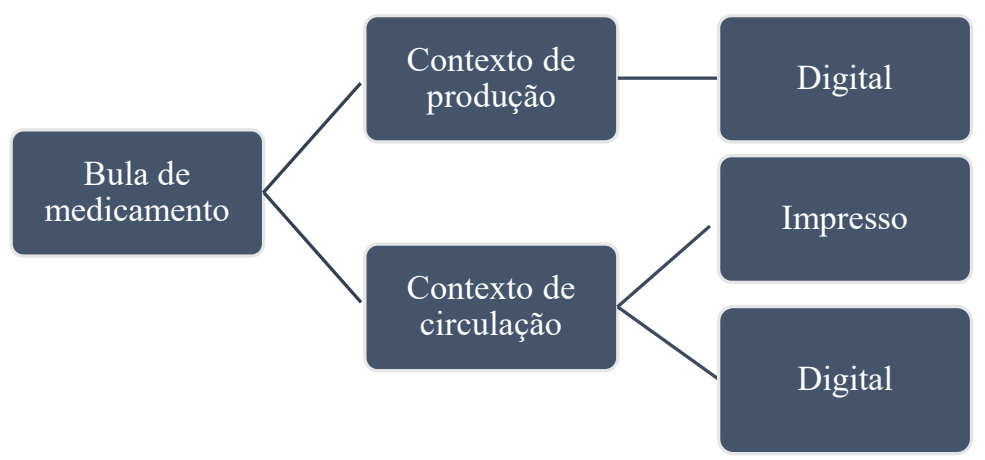

Esquema 3. Género bula de medicamento e as dimensões contexto e tipo de suporte

Importa também sublinhar que embora a bula de medicamento circule inserida numa embalagem de medicamento, esta última não constitui suporte da primeira, mas é suporte do género rótulo de embalagem de medicamento.

Conforme esclarece Marcuschi (2003: 29):

Este é um caso interessante, pois no geral a embalagem não seria tida como um suporte. Contudo, tomamos a embalagem como um suporte na medida em que nas embalagens podem estar vários gêneros. Embalagens de produtos comestíveis muitas vezes trazem não só o rótulo do produto, mas uma receita.

Quanto ao graffiti, o contexto produção dos exemplares inscritos no género está intrinsecamente associado ao suporte manuscrito. Embora os textos possam posteriormente circular em suporte digital, o contexto de circulação mais habitual e que está vinculado ao género é também o manuscrito, como se representa no esquema que se segue.

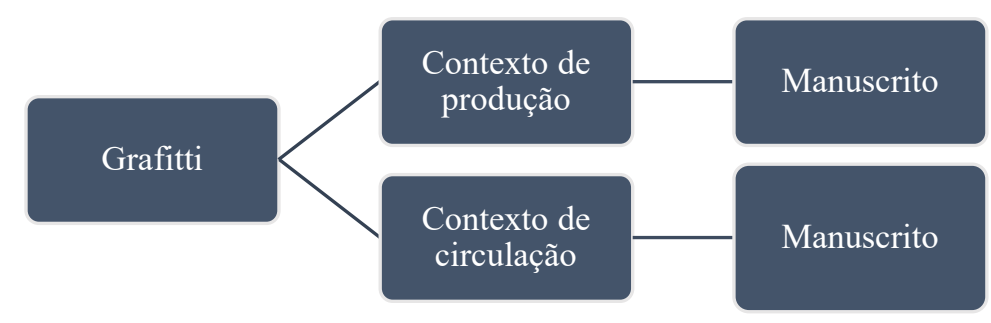

Esquema 4. Género graffiti e as dimensões contexto e tipo de suporte 
De acordo com Campos (2007: 252), "o graffiti é uma forma de linguagem ligada umbilicalmente ao seu suporte que, independentemente da sua qualidade, deve estar exposta no espaço público e, de preferência, com bastante visibilidade". Neste sentido, embora a etiqueta graffiti possa designar formas de expressão e usos da linguagem bastante diversificados, esta remete inequivocamente para textos produzidos num tipo de suporte específico, ainda que o formato do mesmo possa ser bastante variável (paredes, chão, mobiliário urbano, etc.) (cf. Rosa, 2018; Rosa, Ricciardi \& Gonçalves, 2019). Deste ponto de vista, apesar de as tecnologias possibilitarem o registo e divulgação do graffiti em suporte digital, o género está associado, tanto na produção como na circulação, ao suporte manuscrito em formatos pouco convencionais, tendo em conta que a função primeira destes não é, geralmente, a de suporte textual. Para Marcuschi (2003: 29), estes exemplos de formatos que assumem ocasionalmente a função de suporte constituem suportes incidentais:

Tal como lembrado acima, os suportes aqui denominados incidentais são apenas meios casuais que emergem em situações especiais ou até mesmo corriqueiras, mas não são convencionais, como os apontados no item anterior. Ninguém nega que uma porta de banheiro porta textos, mas isto não é comum em todos os banheiros, como não é comum todos terem seus corpos com inscrições ou que as calçadas, as paredes e os muros em geral estejam cheios de inscrições. Em cidades ou locais de maior cuidado, evitam-se inscrições nestes lugares, o que indica que não são suportes convencionais para textos escritos.

Marcuschi (2003: 29)

No entanto, embora uma parede possa ser um suporte do graffiti, poderá ser também um suporte de um outro suporte, como, por exemplo, de um cartaz. Neste caso, como se discute em Rosa (2020: 63), temos um suporte que acolhe outro, ou seja, a parede é suporte do cartaz que, por sua vez, pode ser suporte de diferentes géneros, ainda que, por vezes, a etiqueta genérica possa sugerir que suporte e género coincidem, como, por exemplo, no cartaz cinematográfico. Na perspetiva de Marcuschi:

O mais importante neste caso é distinguir entre suporte e gênero, o que nem sempre é fácil pela ausência de limites naturais. Há quem sustente que dicionários e enciclopédias sejam suportes ou portadores de texto, mas isso não é correto porque eles são gêneros e não suportes. Eu mesmo, em trabalhos anteriores, havia identificado o outdoor como gênero, o que ainda é feito por vários autores, em especial nos livros didáticos, mas hoje admito claramente que o outdoor é um suporte para vários gêneros, com preferência para publicidades, anúncios, propagandas, comunicados, convites, declarações, editais. Não é qualquer gênero que aparece num outdoor, pois esse é um suporte para certos gêneros, preferencialmente na esfera discursiva comercial ou política.

Marcuschi (2003: 13)

Quanto ao formato e material do suporte, observa-se que há géneros mais ou menos restritivos neste âmbito. Conforme se sintetiza no Quadro 2., o género artigo científico admite diferentes formatos e materiais 
no contexto de circulação. Deste ponto de vista, embora no contexto de produção os exemplares inscritos no género sejam produzidos em suporte digital, por exemplo, em formato Word, no contexto de circulação, os exemplares do género podem circular em formatos associados ao suporte impresso ou em formatos em suporte digital, sendo o PDF, neste último caso, o mais usual. Já na bula de medicamento, tal como no artigo, os exemplares são produzidos em suporte digital. Contudo, no contexto de circulação mais habitual, isto é, na comercialização de medicamentos, os exemplares do género circulam apenas em suporte impresso no formato folheto, sendo este em papel. Relativamente à entrevista, verifica-se que é um género bastante flexível neste âmbito, tendo em conta que os formatos e materiais se adequam aos diferentes tipos de suporte que o género admite. No que respeita ao graffiti, embora o género esteja associado ao suporte manuscrito, tanto na produção como na circulação, admite uma grande diversidade de formatos e materiais, sendo que estes não são geralmente convencionais, constituindo objetos que cumprem ocasionalmente a função de suporte, ou seja, suportes incidentais, nos termos de Marcuschi (2003: 29).

Tendo em conta a discussão elaborada ao longo do presente artigo, retomamos, no quadro 2, uma proposta de caracterização dos géneros em função do suporte, tendo em conta a distinção entre contexto de produção e contexto de circulação, já apresentada em Rosa (2020).

\begin{tabular}{|c|c|c|c|c|c|c|c|c|}
\hline Géneros & \multirow{5}{*}{ 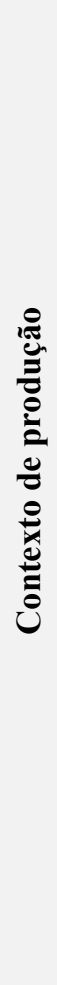 } & Tipo & Formato & Material & \multirow{5}{*}{ 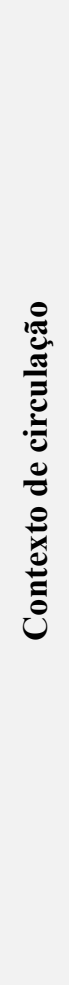 } & Tipo & Formato & $\begin{array}{c}\text { Materi } \\
\text { al }\end{array}$ \\
\hline $\begin{array}{c}\text { Artigo } \\
\text { científico }\end{array}$ & & Digital & $\begin{array}{l}\text { Word (ou } \\
\text { outro } \\
\text { processador } \\
\text { de texto) }\end{array}$ & Virtual & & $\begin{array}{c}\text { Digital } \\
\text { Impresso }\end{array}$ & $\begin{array}{c}\text { PDF } \\
\text { Ebook } \\
\text { Revista... }\end{array}$ & $\begin{array}{c}\text { Virtual } \\
\text { Papel }\end{array}$ \\
\hline $\begin{array}{c}\text { Bula de } \\
\text { Medicamento }\end{array}$ & & Digital & $\begin{array}{l}\text { Word (ou } \\
\text { outro } \\
\text { processador } \\
\text { de texto) }\end{array}$ & Virtual & & $\begin{array}{l}\text { Digital } \\
\text { Impresso }\end{array}$ & $\begin{array}{c}\text { PDF } \\
\text { JPG } \\
\text { Folheto } \\
\ldots\end{array}$ & $\begin{array}{c}\text { Papel } \\
\text { Virtual }\end{array}$ \\
\hline Entrevista & & $\begin{array}{c}\text { Oral } \\
\text { Digital } \\
\text { Impresso } \\
\text { Manuscrito }\end{array}$ & $\begin{array}{c}\text { Ondas } \\
\text { sonoras } \\
\text { Word (ou } \\
\text { outro } \\
\text { processador } \\
\text { de texto) } \\
\text { Livro } \\
\text { Caderno }\end{array}$ & $\begin{array}{c}\text { Ar } \\
\text { Virtual } \\
\text { Papel }\end{array}$ & & $\begin{array}{c}\text { Oral } \\
\text { Digital } \\
\text { Impresso } \\
\text { Manuscrito }\end{array}$ & $\begin{array}{l}\text { Revista } \\
\text { PDF } \\
\text { Ebook } \\
\text { Podcast }\end{array}$ & Vários \\
\hline Graffiti & & Manuscrito & $\begin{array}{c}\text { Mural } \\
\text { Parede } \\
\text { Rodapé... }\end{array}$ & $\begin{array}{c}\text { Betão } \\
\text { Plástico } \\
\text { Ferro... }\end{array}$ & & Manuscrito & $\begin{array}{c}\text { Mural } \\
\text { Parede } \\
\text { Rodapé... }\end{array}$ & $\begin{array}{c}\text { Betão } \\
\text { Plástico } \\
\text { Ferro... }\end{array}$ \\
\hline
\end{tabular}

Quadro 2. Géneros e as dimensões do suporte 


\section{Considerações finais}

Qualquer produção textual implica um suporte e este constitui uma propriedade inerente a todos os géneros. Neste artigo, considerando a necessidade de abordar esta questão pouco trabalhada no âmbito dos estudos dos géneros, apresentou-se uma proposta de classificação das dimensões do suporte, refletindo-se sobre o modo como estas se relacionam em diferentes géneros de texto. Na proposta de classificação apresentada, distinguimos quatro dimensões: contexto, tipo, formato e material. Como se referiu, o objetivo não é propor uma categorização estanque, mas dar conta de algumas das relações que podem ser estabelecidas entre géneros de texto e suporte, ou seja, as possibilidades e impossibilidades destas relações.

Concluímos que as relações entre géneros e o suporte não são aleatórias, pois cada género tem os seus tipos, formatos e materiais, que, por sua vez, variam consoante o contexto (produção e circulação). Tendo em conta os quatro géneros considerados, observou-se que alguns géneros admitem diferentes suportes, não sendo comprometido o seu funcionamento social, se houver uma mudança, como é o caso dos géneros artigo científico e entrevista. No entanto, atentou-se que a entrevista, comparando com o artigo científico, é um género mais flexível no que se refere ao tipo de suporte, formato e materiais, sendo que poderão ser ou não coincidentes nos contextos de produção e circulação. Já a bula de medicamento é um género mais restritivo neste âmbito, dado que o contexto de circulação dos textos mais usual implica um tipo de suporte, um formato e material específicos. Quanto ao graffiti, apesar de admitir uma grande diversidade de materiais e formatos, o género está intrinsecamente associado ao suporte manuscrito, constituindo este uma propriedade diferenciadora e caracterizadora do género. Isto significa, por um lado, que os géneros podem ser mais restritivos no que respeita ao suporte em que os textos são produzidos e circulam e, por outro, que o suporte pode constituir uma propriedade específica de um género, como é no caso do graffiti (cf. Rosa, 2020: 63).

Por fim, sublinhamos que esta é uma proposta em via de consolidação, sendo, desta forma, ainda necessário estabilizar a classificação apresentada através de trabalhos em que se considerem outros géneros, bem como investigar a possibilidade de esta propriedade genológica implicar outras dimensões.

\section{Referências :}

Adam, Jean-Michel (2011) Les textes: types et prototypes. (3.e éd.) Paris: Armand Colin 1a éd. Éditions Nathan. Bronckart, Jean-Paul (1996) Genres de textes, types de discours et opérations psycholinguistiques. In Voies livres, vol. 78, Lyon, pp. 1-20. Disponível em: https://archive-ouverte.unige.ch/unige:37323

Bronckart, Jean-Paul ([1997] 1999) Atividade de linguagem, textos e discursos: por um interacionismo sóciodiscursivo. Trad. Anna Raquel Machado. São Paulo: EDUC.

Bronckart, Jean-Paul (2005) Os gêneros de Textos e os Tipos de Discurso como Formatos das Interações Propiciadoras de Desenvolvimento. In Menendez, F., Análise do Discurso. Lisboa: Hugin, pp. 37-39.

Campos, Ricardo (2007) Pintando a cidade: uma abordagem antropológica ao graffiti urbano. Tese de Doutoramento em Antropologia Visual. Lisboa: Universidade Aberta. Disponível em: http://hdl.handle.net/10400.2/765

Coutinho, Maria Antónia (2005) Para uma linguística dos géneros de texto. In Diacrítica, n. ${ }^{\circ}$ 19, vol. 1, pp. 7388. Disponível em: http://cehum.ilch.uminho.pt/cehum/static/publications/diacritica_19-1.pdf

Coutinho, Maria Antónia (2006) O texto como objeto empírico: consequências e desafios para a linguística. In Veredas. Disponível em: http://www.ufjf.br/revistaveredas/files/2009/12/artigo076.pdf

De Angelis, Rossana \& Gonçalves, Matilde (no prelo) Contraintes et enjeux de la matérialité numérique : les logiciels d'autocomplétion. In Revue Sémen 48.

De Angelis, Rossana (2018) Textes et textures numériques. Le passage de la matérialité graphique à la matérialité numérique. In Signata: Sémiotique de l'écriture., pp. 459-484. Disponível em: http://journals.openedition.org/signata/1675 
De Angelis, Rossana (2016) De l'objet linguistique à l'objet d'écriture. In Dossiers $d^{\prime}$ Hel, n. ${ }^{\circ} 9$ Écriture(s) et représentations du langage et des langues, pp. 317-332. Disponível em: https://hal.archives-ouvertes.fr/hal01305406

Gonçalves, Matilde (2011) Espécie de texto: contributo para a caraterização do sítio web. In Hipertextus, pp. 112. Disponível em: http:/www.hipertextus.net/volume7/02-Hipertextus-Vol7-Matilde-Goncalves.pdf

Gonçalves, Matilde (2013) Organização textual e (des)linearidade: o caso dos sítios web. In Estudos $\begin{array}{llllll}\text { Linguísticos/Linguistics } & \text { Studies, } & 8 & \text { pp. } & 133-147 . & \text { Disponível }\end{array}$ http://clunl.fcsh.unl.pt/wpcontent/uploads/sites/12/2017/07/M.Gon\%C3\%A7alves.pdf

Gonçalves, Matilde \& Magalhães, Miguel (2019) "Corpus e géneros textuais nas práticas de divulgação de ciência ou as novas hierarquias na construção do conhecimento". In Revista da Associação Portuguesa de Linguística 5, pp. 145-157. https://doi.org/10.26334/2183-9077/rapln5ano2019a11

Gonçalves, Matilde \& Rosa, Rute (2019) O suporte digital na leitura e compreensão textual. In A. M. Ferreira, C. Morais, M. F. Brasete, \& R. L. Coimbra (Eds.), Pelos mares da língua portuguesa 4 (Vol. 4, pp. 571587). UA Editora, Universidade de Aveiro, Serviços de Biblioteca, Informação Documental e Museologia.

Jeanneret, Yves, \& Souchier, Emmanuël. (2005) L'énonciation éditoriale dans les écrits d'écran. Communication et Langages, (145), 3-15. Disponível em https://www.persee.fr/doc/colan_0336$1500 \_2005$ num_145_1_3351

Lévy, Pierre (1996) O que é virtual? Trad. Paulo Neves. São Paulo: Ed. 34.

Maingueneau, Dominique (2002a) Análise de textos de comunicação. São Paulo: Cortez Editora.

Maingueneau, Dominique. (2002b) Un genre de discours. In Dardy, C.; Ducard, D.; Maingueneau, D. Un genre universitaire: le rapport de soutenance de thèse. Paris, PUF, pp. 49-86.

Marcuschi, Luiz Antônio (2003) A questão do suporte dos gêneros textuais. In $D L C V$ - vol. 1, N. ${ }^{0}$ 1, João Pessoa, pp. 9-40. Disponível em: https://periodicos.ufpb.br/ojs2/index.php/dclv/article/view/7435

Miranda, Florencia (2010) Textos e géneros em diálogo: uma abordagem linguística da intertextualização. Lisboa: FCT/FCG.

Miranda, Florencia (2017) Análise interlinguística de gêneros textuais: contributos para o ensino e a tradução. In DELTA., 33.3, pp. 811-842. ISSN 0102-4450. Disponível em: http://dx.doi.org/10.1590/0102445056244276863621

Rastier, François (2001) Arts et sciences du texte. Paris: PUF.

Rosa, Rute (2018) The attribution of genre tags: the graffiti case. In Coutinho, M. A., et al. (Eds.). Grammar and Text: Selected Papers from the 10th and 11th Fora for Linguistic Sharing. Newcastle upon Tyne: Cambridge Scholar Publishing: pp. 88-104.

Rosa, Rute, Ricciardi, Natalia \& Gonçalves, Matilde (2019) O papel do graffiti na construção do (contra)poder: um estudo comparativo Portugal/Argentina. In M. A. Marques e S. Guimarães de Sousa (eds)., Linguagens de Poder. 1. ${ }^{a}$ ed. V. N. Famalicão: Edições Húmus, pp. 263-281. ISBN 978-989-755-430-8.

Rosa, Rute (2020) A noção de padrão discursivo: textos e géneros em análise. Tese de Doutoramento em Linguística. - Texto e Discurso. Faculdade de Ciências Sociais e Humanas da Universidade NOVA de Lisboa. Disponível em: http://hdl.handle.net/10362/97668

Silva, Paulo Nunes da \& Rosa, Rute (2019) O plano de texto do artigo científico: caracterização e perspetivas didáticas. In DELTA, São Paulo, vol. 35, n. ${ }^{\circ}$ 4. Disponível em: http://dx.doi.org/10.1590/1678460x2019350409 